\title{
Curriculum at forty below: a phenomenological inquiry of an educator/ explorer's experience with adventure learning in the Arctic
}

\author{
Charles Miller*, George Veletsianos and Aaron Doering \\ Learning Technologies, University of Minnesota, Minneapolis, USA \\ (Received 13 November 2007; final version received 6 August 2008)
}

\begin{abstract}
Grounded in the theoretical approaches of experiential learning and inquiry-based learning, adventure learning (AL) is a hybrid distance education approach that seeks to transform the experiences of students by having learners explore real-world issues and pursue answers to their own questions in an authentic, anchor-based environment. In this article we present a theoretical overview of AL, provide a brief summary of recently examined AL impacts in the classroom, and use a phenomenological lens to examine the experience of an educator/explorer who traveled by dogsled over 3000 miles across the Arctic to engage students and teachers from around the world in a truly authentic learning context. We conclude by offering recommendations for teachers who wish to embark on their own unique AL experiences with their students (without necessarily having to travel to the Arctic).
\end{abstract}

Keywords: adventure learning; experiential learning; hybrid online distance education; inquiry-based learning; phenomenological inquiry

No wages ... bitter cold ... long months of complete darkness ... constant threat of danger ... outcome unpredictable ... unparalleled student interest ... abundant learning opportunities ... lasting collegiate partnerships ... real-world application of educational technologies. (PolarHusky, 2004, excerpt from the Arctic Transect 2004 call for educators)

Forty-five degrees below zero at 68 degrees north latitude. 11:35 p.m. The wind is screaming under, over, and along both sides of the tent. Jordan ${ }^{1}$ lay motionless, buried inside two layers of goose-down sleeping bags, one smelling of a hole burnt in the side from a butane-stove fire the night before. Having spent the last several hours battling the satellite system and pulling batteries in and out of his sleeping bag so as to heat them up enough for downloading data, Jordan's looming thoughts of lost and damaged trail data were scattered and painted about the confines of the rumbling tent walls. Every muscle of his frame tensed tighter and tighter with each breath. His body hurt from being scrunched over within the tent, working on the trail report for the last eight hours. It was like 'standing in a deep freeze, day in and day out to deliver an educational dream.' Regardless, nothing else mattered except getting the trail report sent out to millions of students. Once the trail and report data were sent, all Jordan could do was wait ... wait for the 5:00 a.m. howl of the energetic huskies, anxious to trek another 20-30 miles the following Arctic day.

In January 2004, Jordan, a professor of learning technologies at a large Midwestern university, and five teammates trekked across the Arctic with 31 polar huskies to provide an authentic and collaborative educational environment for approximately 3 million

\footnotetext{
*Corresponding author. Email: mill1957@umn.edu
} 
students and educators worldwide (Doering, 2007). Arctic Transect 2004: An Educational Exploration of Nunavut (AT2004) was an online adventure learning (AL) program designed to engage learners with authentic content through a real-time adventure: a 3000mile dogsled expedition across Nunavut, the newest Canadian territory bordering the Arctic Ocean. Upon completion of the expedition and the team's arrival in Pond Inlet, Nunavut, after 156 days of travel, the AT2004 project was a collaborative triumph in online distance education. Over 3 million students and teachers from around the world participated in the online environment and collaborated with the explorers, invited speakers, and fellow students in the 18-week curriculum. The widespread success of the expedition and award-winning online environment solidified funding for a five-year initiative to transect the Arctic regions of the globe and promote environmental awareness through conservation education.

The internationally acclaimed AT2004 project provided a free 18-week, K-12 curriculum and online educational environment for students and educators around the globe. The Washington Post awarded the AL site (www.polarhusky.com) an 'A' (Szadkowski, 2004) and the eLearning Advocate noted, 'This is what online learning is all about. Transporting students to the Arctic where they can experience a learning adventure in real-time' (Hall, 2004). A participating AT2004 middle-school teacher, commenting on the real-world interaction with the curriculum in the online environment, stated:

This is history in the making and that it's delivered to us daily - it's just a phenomenon. I have never seen students motivated to learn like this! That is, where they are motivated to go online into the environment and share their experiences with other students from around the world. (personal communication, May 2004)

In this article we explore an overview of the AL framework for hybrid online collaborative education, present a brief summary of recently examined impacts of AL in the classroom, use a phenomenological lens to illustrate the enduring experience of an educator/explorer traveling by dogsled to provide authentic educational context, and discuss several recommendations for teachers who wish to embark on their own unique AL experience with their students (without necessarily having to travel to the Arctic). Moreover, we offer perspectives and insights on the following questions: How was a hybrid educational environment able to engage over 3 million learners in a short (sixmonth) window? What is the experience of providing this nature of collaborative realworld learning? And, specifically, what is the experience of traversing the Arctic to engage students and teachers from around the world in a truly authentic learning context?

It is important to note that this article was designed to take the reader through a unique experience by exploring $\mathrm{AL}$ from a number of perspectives, chiefly that of the educator/explorer. We have found educators to become especially motivated and energized when learning about AL through our presentations at conferences, visits to local schools and communities, published scholarly articles, and media showcases (e.g., television, state fairs, online case studies). The instructional and educational experiences illustrated in this article could not have been conceived without contemporary advances in geospatial and communication technologies; thus, in examining these experiences we present a unique perspective to traditional online learning. However, the intricate and extraordinary experience of providing AL to learners (i.e., from the perspective of the educator in the field) often takes second stage to research on student impacts and pedagogical orientations of the approach. For this reason, we have organized this article into three distinct sections: 
(1) a brief theoretical overview of AL and student impacts;

(2) a phenomenological examination and narrative of the remarkable experience one educator faced when embracing the heart and essence of AL;

(3) practical guidelines for distance educators to integrate the AL framework with their students.

The phenomenological, adventure-based narrative employed in these pages may seem atypical in the field of distance education as the tone shifts from scholarly inquiry to firstperson narrative. However, we believe examination of the AL educator/explorer experience represents an important addition to the emergent body of AL research. We believe it is essential for distance educators to understand the foundations and integration strategies of instructional approaches that engage learners and promote critical thinking by examining the experiences of fellow educators pushing the limits of traditional online learning.

\section{An overview of AL}

AL is a 'hybrid distance education approach that provides students with opportunities to explore real-world issues through authentic learning experiences within collaborative online learning environments' (Doering, 2006, p. 197). Grounded in the theoretical approaches of experiential learning and inquiry-based learning, AL seeks to transform the experiences of students by having learners pursue answers to their own questions and issues in an authentic, anchor-based environment (Doering, 2007). In experiential learning, a learner creates meaning from direct experiences and reflections (Kolb, 1984); such is the goal of AL within the classroom. The inquiry-based approach to learning with AL involves learners exploring answers to self-generated questions rather than focusing on memorizing and regurgitating isolated, irrelevant facts. Additionally, AL affords learners a real-time authentic online learning experience concurrently as they study the AL curriculum. Both the curriculum and the online classroom are developed to foster students' abilities to inquire via 'identifying and posing questions, designing and conducting investigations, analyzing data and evidence, using models and explanations, and communicating findings' (Keys \& Bryan, 2001, p. 632).

Unlike traditional learning environments, AL does not position teachers in the instructor/ facilitator/designer role of the learning space. Rather, AL uses both face-to-face and an online learning environment for students, teachers, experts, and AL team members to collaborate with one another and explore the issues at hand (e.g., conservation, global warming, water preservation, local environmental concerns). Traditional hierarchical classroom roles are blurred in AL environments as students' roles transform from content absorbers toward reflective practitioners, creating innovative opportunities for learning, teaching, and motivation (Doering, 2007).

At this point it is important to stress that AL is more than simply an online media journal of a person's desire to explore the Earth, with education as the final phase of development. Rather, curriculum and collaboration are the heart of an AL project. The AL framework (see Figure 1), created from five years of designing, developing, delivering, and assessing AL environments, identifies the following characteristics and principles of a successful AL environment (Doering, 2006):

(a) a researched curriculum grounded in problem-solving, (b) collaboration and interaction opportunities between students, experts, peers, and content, (c) the utilization of the Internet for curriculum and learning environment delivery, (d) the enhancement of curriculum with 


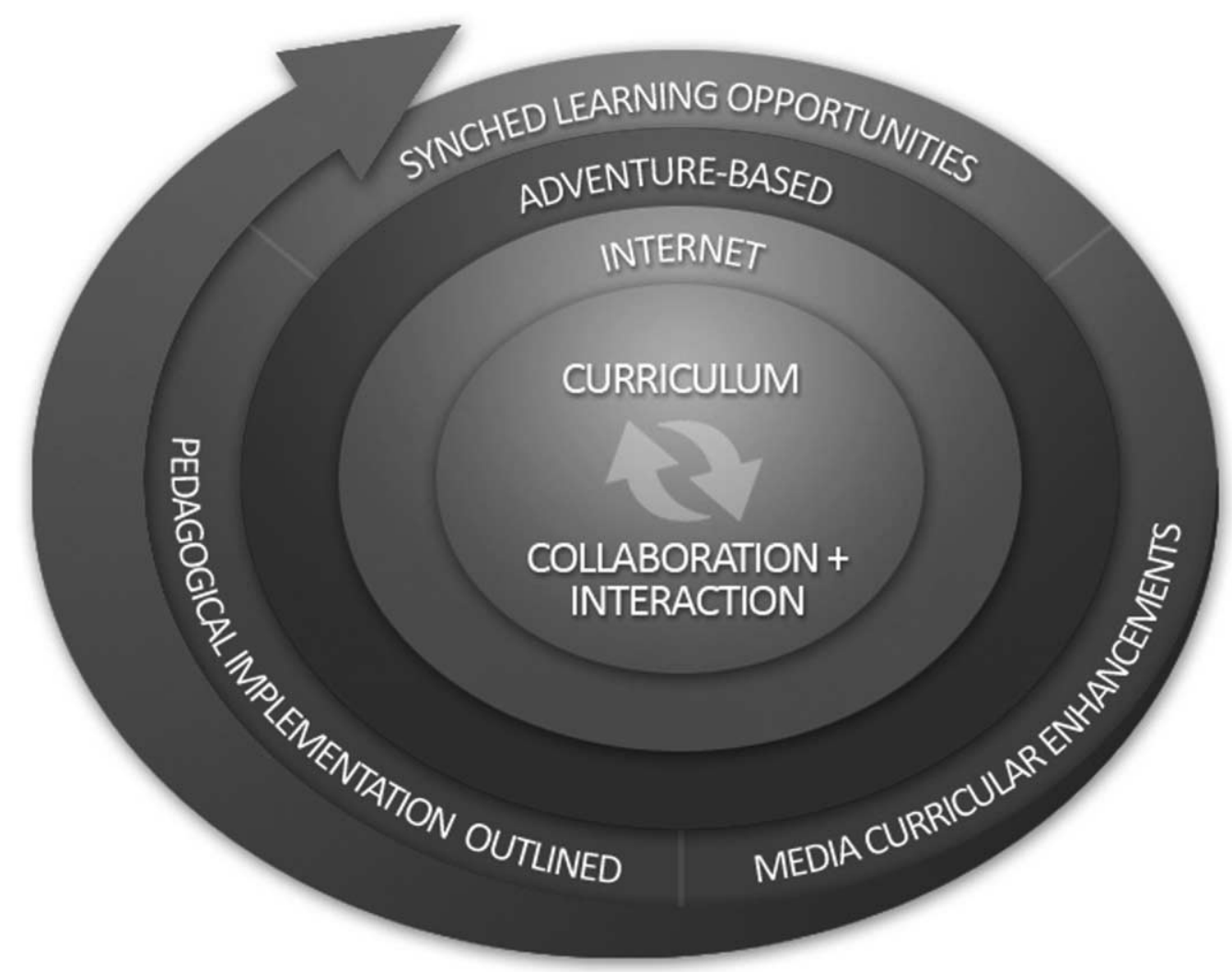

Figure 1. Adventure learning model (adopted from Doering, 2006, p. 201).

media and text from the field in a timely manner, (e) synched learning opportunities with the AL curriculum, (f) pedagogical guidelines of the curriculum and online learning environment, and $(\mathrm{g})$ education that is adventure-based. (p. 200)

These seven principles can be used collectively as a guide for teachers and instructional designers who wish to provide transformative learning opportunities for students within an online distance education experience.

Parallel to the development of the curriculum, the AL online learning environment is designed to support the curricular goals through the development of several online spaces. These spaces afford collaboration among learners, interaction with real-time authentic media from the field (i.e., the location of travel), delivery of authentic media that supports the curricular learning, and an overview of pedagogical principles and support for successful teaching of AL (Doering, 2006). One example of the seamless connection between the curriculum and the online learning environment is the weekly trail update. Every Friday during the expedition an 'education day' is taken in the field, where the explorers and educators stop traveling to organize and edit the collected media from the week, write the trail report, and send the report to education basecamp via satellite technologies. The basecamp manager then uploads the trail report and supportive media to the online learning environment for teacher and student access by early Monday morning. All aspects of the trail report are designed to support the curricular goals. For example, in a curricular unit 
focused on climate change, all photos, movies, QuickTime Virtual Reality (QTVR) files, interviews, and trail reports reinforce the climate lessons. Concurrently, the education basecamp manager updates the online learning environment content, schedules an expert speaker for the week to participate in an Expert Chat, moderates the Collaboration Zones where students from around the world collaborate on student-driven projects, and answers all questions from students and teachers to support learning and integration, respectively. The process of designing and delivering an AL program is intensive, but valuable.

\section{Summary of examined classroom and learner impacts}

Research on the classroom and student impacts of AL is in its infancy, with several investigations currently underway and a series of expeditions and exciting AL programs planned for the next several years. Recent studies by the authors have examined teacher integration models for AL; student experiences with authentic geospatial technologies; and the collaborative, authentic, and motivational affordances AL provides within $\mathrm{K}-12$ classrooms.

Doering and Veletsianos (2008) investigated the methods teachers use to integrate AL in their classrooms and the ways students respond to and experience such integration models. Data revealed that teachers utilized four divergent integration approaches focusing on curriculum, activities, standards, and media. The variability discovered in these four approaches highlights the versatility and adaptability of the AL approach. Moreover, student experiences across these four integration models, although varied, were predominantly positive, with students being excited, engaged, and motivated with the authentic and problem-based tasks employed within the AL environment. Additionally, it was found that students valued their connections with the explorers, invited experts, and peers through social affordance features of the AL environment such as Send-A-Note (i.e., students send comments and ask questions to the team through a form-based tool that is checked and updated when on the trail), Expert Chats (i.e., students chat with invited topic experts and explorers to highlight and expand upon current issues within the curriculum in a guided setting), and Collaboration Zones (i.e., students of all ages and geographic locations collaborate and learn from one another in an online forum as they post their own research, ideas, and opinions tied to the current curricular topic and expedition activities).

In addition to student and teacher experiences with integration, Doering and Veletsianos (2007) also investigated student interaction with real-time and authentic geospatial data provided through an AL environment. Geospatial technologies allow individuals to view and examine the world through multiple layering of data within a spatial environment (e.g., Google Earth, ArcExplorer). For example, students can study and explore the San Francisco region by viewing population density and seismic activity data overlays superimposed on a three-dimensional map of the city. The researchers found that collaborative use of real-time authentic data in the context of geospatial technology as a constructivist tool in the K-12 classroom had a positive impact on students learning geography. Specifically, the use of geospatial data provided via the AL environment (a) assisted learners in developing a sense of place, (b) provided opportunities for the co-construction of knowledge, (c) motivated students to explore geographic locations of interest, and (d) assisted learners in understanding the geography of the region of study.

Finally, Doering (2007) examined more than 300 cases of teacher and student use of an AL environment (i.e., AT2004) in K-12 classrooms to identify how teachers facilitated the synched curriculum and online classroom with their real-world classroom environments. Results indicated three affordances of the AL program: 
(1) online dialogue and collaboration opportunities (i.e., students collaboratively interacted with and experienced a different culture through shared videos, photos, audio files, and presentations, in addition to communicating with experts and explorers);

(2) inquiry-based curriculum and authentic real-time content (i.e., the experience, explore, and expand subsequent levels of inquiry required learners to explore issues in greater depth through a wide range of investigations and resources);

(3) motivation for inquiry through multiple modes of media (i.e., the multiple modes of authentic and real-time media motivated students to investigate content through varied lenses).

These affordances support and promote the belief that AL has the potential to change the existing architecture of the traditional K-12 classroom by providing access to and the opportunity to interact with authentic data, content, people, and real-world situations.

\section{Delivering an AL learner experience}

Although the aforementioned AL framework presents a model for designers to follow when designing an $\mathrm{AL}$ environment, the role of the educator/explorer responsible for generating and providing the authentic context of the AL project can be very different, and hopefully an inspiring experience to share with other distance educators. In the following sections, we use a phenomenological lens to examine and illustrate the experience of an educator/explorer who traveled 3000 miles by dogsled across the Canadian Arctic to provide teachers and learners with an authentic and transformative learning opportunity.

\section{Phenomenological inquiry of AL}

Phenomenology involves the exploration of human experience through conscious, retrospective reflection (Jonassen, Campbell, \& Davidson, 1994; Patton, 2002; van Manen, 1990). The nature of phenomenological inquiry seeks to examine, understand, and interpret observable, yet special, events in our everyday life, with the benefit of sharing the meaning of these phenomena with others. The experience of a phenomenon can be explained by a close examination of the four life-world existentials of body, time, space, and relations with others. Experiences are individual constructions that illustrate the essence of an event (Jonassen et al., 1994) and are embedded into a particular context, transforming individual psychological states (Hassenzahl, 2004). Husserl (1913) stated that only through our conscious awareness can we begin to describe our perceptions and experience. For example, how do you experience anxiety? In this instance, anxiety is the phenomenon of interest and the word anxiety does not describe the experience of being anxious; rather, it is a psychological abstraction. What do you experience when you are anxious? How do your palms feel? Do your muscles become tense? Is it difficult to concentrate on everyday tasks? Notice that we are examining the meaning of anxiety, the experience of being anxious, as opposed to accepting the abstract word (i.e., descriptor) as conclusive (Polkinghorne, 1989).

There are three important facets of phenomenological inquiry: first, the idea of examining a phenomenon is closely tied to natural attitude, which refers to the way we perceive ourselves in the world. Phenomenologists strive to study individuals as part of their natural attitude, as part of their natural world where no artificial conditions are set, no variables are 
manipulated, and no laboratory is involved. Second, phenomenology encompasses the idea of reductionism (Giorgi, 1997). In this process the researcher undergoes a process of bracketing, where he/she removes him/herself from the experience and examines it as an outside observer. The researcher must consider his/her data (e.g., interviews, lived experience descriptions) as true descriptions of the experience without imposing his/her own personal experiences upon those. Phenomenology is 'discovery oriented; and in order to discover meanings in the data, one needs an attitude open enough to let unexpected meanings emerge' (Giorgi, 1997, p. 247). Finally, and most importantly in our view, Giorgi (1997, p. 246) and van Manen (2001, p. 177) describe the essence of an experience as the 'true being of a thing.' The essence of an experience can be derived through a process where the researcher questions the phenomenon by excluding identified themes: Is theme X really part of the experience? Does the phenomenon exist without theme $X$ ? It is also important to note that no one theme is monolithic and no one theme can describe the experience by itself. Rather, the set of derived themes are monolithic as a whole and describe the lived experience of the phenomenon.

\section{Description of phenomenological inquiry}

The lived experience of delivering distance education from the Arctic was derived from three phenomenological interviews. The interviews lasted approximately 45 minutes each and were conducted six months after returning from the expedition. Miller began each interview by directly asking about the experience of delivering distance education from the Arctic. Thereafter, we probed the comments that were made by the interviewee. For example, if Jordan said, 'I was exhausted and freezing,' we would probe the feelings of exhaustion and freezing to illustrate a lived experience description. This process was used throughout each interview. The interviews were recorded via a USB digital recorder and transcribed into a database of quotations.

\section{Transcript analysis and theme statement generation}

Once the interviews were gathered and transcribed, our approach involved a holistic, global review of all data before analysis, important for establishing a constitution of the parts (Giorgi, 1997). Next, the transcripts were re-read and any analytical descriptions and reflective comments were removed. Interview data were categorized into meaning units (i.e., relevant pieces of the experience captured in the subject's everyday language) with an unspecified attitude. Once the meaning units were documented within each interview, they were re-examined and re-described in terms relevant to the disciplinary orientation of the study. Using NVivo software to aid in highlighting common meaning units, descriptions that fit particular themes were grouped together and a theme statement was developed for each group. The themes were then scrutinized and either discarded or employed to describe the experience of delivering AL from the Arctic. Finally, themes were used to re-examine the data and pinpoint variations of the phenomenon.

The theme statements were developed into a hermeneutic phenomenological study in which we attempted to express the experience in an evocative manner drawing materials from numerous contemporary sources using examples: 'Examples [are] the way in which we address the phenomenological themes of a phenomenon so that the "invariant" aspect(s) of the phenomenon itself comes into view' (van Manen, 2001, p. 122). When possible, Jordan's actual language and verbiage are used in the following sections to portray an accurate and vivid description of the experience. 


\section{The experience of delivering AL from the Arctic}

In the following section we identify and describe the theme statements generated from the phenomenological interviews. The colorful style of writing employed in these sections is meant to embody the nature of the interviews and help illustrate the experiences. It is important to note that these themes are interdependent and overlapping. Specifically, we identified the following themes to illuminate the experience of traversing the Arctic to engage students and teachers from around the world in a truly authentic learning context - AL:

(1) Education must be the goal

(2) In a blizzard, it is difficult to write

(3) Fighting the technology

(4) It's not like you can just throw something in the microwave

(5) What am I doing out here?

\section{Education must be the goal}

One of the greatest challenges an explorer faces on an expedition is the unrelenting trial of uncertainty - the uncertainty of gear functionality, the uncertainty of endurable temperatures, the uncertainty of food conservation, and ultimately the uncertainty of whether or not one will make it through the night to explore another day. However, it must be made certain that delivering an education program from the trail is the goal of the program and that everyone, regardless of their backgrounds, understands this goal.

On the expedition, 'there is a constant battle between travel, making the daily miles, and delivering the best education program possible.' When you have six team members, both personal goals and mission goals will inevitably collide. This collision causes 'tension in your daily life on the trail' as some team members are trying to break records for how many miles can be traveled in a single day, while others are trying to create and deliver a quality education program amidst the 'hectic nature of Arctic life.'

There is not only the battle with the temperatures and with the cold and with life on the trail in general, but there is the conflict between personalities and between egos and between what the main goal of the program is.

However, when the expedition team was featured in the media (e.g., television spots, National Public Radio, magazine features), education was the main goal. The expedition was not funded by adventure gear companies to see how far the human spirit could travel in subzero conditions. Rather, AT2004 was supported by educational organizations to provide a true adventure learning experience for students and instructors worldwide that would bring awareness of the Arctic region. This is where the money came from and these are the people the team was obliged to satisfy. To ensure (or, at least, help ensure) that education remained the primary goal of the trek, the following six objectives served as the mission statement behind the AL expedition (PolarHusky, 2004):

- Encourage online collaboration on environmental and cultural aspects among students worldwide

- Restore, teach, and open communication on traditional issues between elders and youth

- Strengthen interest in traditional knowledge

- Gather scientific environmentally relevant data 
- Support the appreciation of cultural diversity

- Promote Arctic and environmental awareness.

Nevertheless, when reality set in at 68 degrees north latitude and team members did not share the same goal,

it was a constant struggle, with the team and with myself because you would want to lose your temper, but why? It does no good to get upset in the middle of the Arctic. You could curse at it, but it wouldn't do any good.

For six months and over 3000 miles, Jordan was entangled in this battle, one that often superseded the painful and relentless struggle with the Arctic elements. Blizzards, breaking ice, polar bears, tent fires, food rationing, and $-45^{\circ} \mathrm{F}$ nights were only part of the warfare. 'I had to fight for that [education] and you really have to have a team that has a mission of education and that's the goal where people are working together to make it a success at all costs.'

\section{In a blizzard, it is difficult to write}

For most teachers who use computers to develop and implement their curriculum, an occasional struggle with the laser printer or a skirmish with a USB memory key can put quite a damper on one's instructional efficiency. Try dealing with these most trivial of problems while the tent walls are pounding and snow is piling up the sides of the walls, collapsing in on you.

The wind is just blowing like hell ... the tent is shaking. When it's 40 below and the wind is blowing, the generator never wants to run ... you might have some really great writing for an hour, and then you are fighting with the generator to keep that running. It's hell.

Adding to the fierce blend of tornado-like conditions and temperatures approaching 60 degrees below zero on the other side of the thin tent wall, 'all of the sudden you would get a cramp in your leg or something because you just can't move.' When the physical dimensions of the tent aren't harassing your concentration, your battle with the technology and weather conditions can dampen your enthusiasm for writing an educational trail report.

Blizzards can take their toll on all aspects of expedition life. Gathering data, providing safety to the dogs, transmitting information, communicating with team members, and even sitting in the confines of your tent to write a report are all diminished by the forceful blast of wind and snow. For example, clear your mind and picture sitting in your temperate office while recording a 30- to 40-second daily audio file, writing a 15 - to 20-page weekly report, and editing multiple video and photo files for the complete trail report package to be sent every Friday during 'education day.' Now, imagine doing it in the Arctic during a blizzard. Just as your first paragraph is finished, you can hear the generator puttering outside the tent begin to fail. 'You don't want to put all of your clothes on, but you probably should as you are going out and you are adjusting it and your hands are freezing.' When you return to the tent, all you can do is take a deep breath and think to yourself, 'Aaah, technology ... what a wonderful thing.' However, 'something is always driving you ... driving you to provide the best educational environment within your physical and psychological means.' This indiscernible drive, an 
unremitting force to continue forth, has been experienced by many climbers of the world's tallest peak, Mount Everest:

Allied with enthusiasm and respect for the work in hand it engenders that concentration of mind and energy which acts like a searchlight upon the problem, and seeks solutions for the complicated questions of equipment, tactics, and so forth, involved. (Finch, 1922, p. 413)

\section{Fighting the technology}

Technology is simple. Technology will make things better. Technology will make life better. These are the trouble-free, often convoluted ideals that marketing giants like Apple, Microsoft, and Dell portray to consumers. And, in fact, they may even be true. However, the truth behind these statements holds accurate only in the environments from where they were birthed: businesses, homes, cities, coffee shops, etc.

So, for 3 or 4 hours, I will be working on trying to get 2 megs sent out with the satellite and then I'm getting frustrated. I'm getting very frustrated. I'm getting mad at the technology. I'm getting really tired. It's now midnight. I know I have to get up the next morning to harness the dogs, take down the tent, and get going again.

As we sit writing this manuscript, we could simply pack up our laptops, drive a few miles to the nearest coffee shop, wirelessly connect to its in-house network, and be online browsing for anecdotal sources within the next 10 minutes, all the while enjoying a cup of hot coffee or tea. In the Arctic, connecting with the satellite to send a mere two or three megabytes of photos 'meant a day of fighting the technology and temperatures to try to write up the report.' Technology wasn't so simple:

We would position ourselves in a way that had a clear bearing to the southeast. If we had an iceberg sitting there, we knew we wouldn't be able to transmit the report ... you jump back in and fight with the server because you will connect but it won't transmit data ... you would hope you would get that data-transfer level with the satellite, but you never knew at what level it would be.

Usability is defined as whether a technology affords the effectiveness and efficiency to accomplish a set of tasks in a manner that satisfies the user (Kirschner, Strijbos, Kreijns, \& Beers, 2004; Norman, 1998). In the fields of human-computer interaction, product design, instructional design, usability is a pinnacle element when designing, developing, implementing, and evaluating products and software. Users must be able to complete tasks with ease in order to reach their end goals. In the Arctic, usability is defined as survival and sustainability. 'Although I don't like to draw lines between education and expedition, failure in the technologies for each would mean disaster.' On the expedition side we had 'camp stoves, tents, generators, sleds, dog harnesses, and lanterns.' These technologies accomplished tasks essential for daily survival and travel. The tasks accomplished by the education gear (e.g., satellites, GPS, phones, cameras, laptops, Palm pilots, Flash media) were essential for delivering an education program to millions of students. 'If it's not for the education, why are we here?'

In addition to unwavering team struggles and unrelenting blizzards, "we finally had to get the content sent out.' When the team was able to connect over the intermittent satellite connection for US\$7 per minute, 'it was painfully slow - and I mean painful in the physical sense.' It was not uncommon to spend hours with the satellite in subzero conditions: 
Sending data took three steps. One person would sit in the thundering tent and watch the signal strength on the phone while the other person was outside the tent walls, getting blasted by wind and snow while they listened to the signal beep as they turned the [satellite] dish back and forth to the southeast. You wanted the long, drawn-out beeps - that meant faster and stronger signals. When you couldn't hear the beeps, there was either no signal or too much wind hitting you in the face. Finally, with the signal there, you didn't even know if you could then connect - so you start over. You return to the tent and begin writing again - that is, after your fingers start working again.

Jordan suffered through hardships every day and every night just to shape the data into manageable form and was rarely compensated by the acknowledgement that his data were actually going somewhere. There was no means to connect to the AL online environment and see if the reports, photos, videos, and trail information were being posted. 'Was anyone even watching?' It was as if Jordan was

throwing bottled notes into the Arctic Sea, hoping they would somehow find their way south around Maine, along the costal Atlantic, round Florida, and zigzag their way up the Mississippi River to the University of Minnesota to get published for the world to consume.

\section{It's not like you can just throw something in the microwave}

When you only have 'so much food and so much fuel' and you 'haven't eaten, which is the worst thing you can do because you are getting cold,' your mind begins to daydream about the many amenities of home: a warm bed, a hot meal, luxurious free time to sit and relax. George Finch, an Australian chemist and mountaineer, experienced a similar physical struggle while attempting to summit Mount Everest:

We were deplorably tired ... knees did not always bend and unbend as required. At times they gave out all together ... Weak from hunger and exhausted by that nightmare struggle for life, we were in no fit condition to proceed. (Breashears \& Salkeld, 1999, p. 81)

For Jordan, everything was an elaborate and systematic task. As the trip progressed he began getting 'really tired ... an excruciating burden when trying to accomplish daily tasks.' Even the simple act of making dinner 'was a whole process in itself; it's not like you can just throw something in the microwave.' Aside from creating and sending the daily and weekly education trail reports, which he 'fought like hell to get out,' Jordan always knew that 'there was so much, much more work to be done.' While the other team members slept in, Jordan and his tent mate would industriously rise at 5:00 a.m. to ensure they would have sufficient time to work on the reports, as well as the necessary tasks for survival. 'It's not only getting all the reports out, it's also everything else you have to do such as melting water, making dinner, and feeding and caring for the dogs.' It seemed as if time consciousness had transformed into an obsessive sickness.

According to Breashears (1999) in his autobiographical novel High Exposure, highaltitude mountain climbers experience a similar feeling, although it results from a chemical imbalance rather than mental anxiety and can often be solved through the art of acclimatization:

Acclimatization is a mysterious art, like a kind of alchemy. By climbing and sleeping at progressively higher altitudes - then recovering at a lower altitude - you begin to adjust, if not adapt, your body to the lack of oxygen. Everyone adjusts at different rates, which makes the formula highly subjective. Some don't adjust at all. There comes a point, however, when your body stops adjusting and begins deteriorating. It's for this reason that some call it the Death Zone. (p. 253) 
For Jordan, each day was filled with 'hunger, exhaustion, and the overwhelming weight of tasks to be completed. And there was, most importantly, the trail report.' Education was the goal, but 'staying healthy and staying positive are the mantra.'

\section{What am I doing out here?}

When asked why he wanted to conquer Mount Everest, George Mallory's reported explanation was 'Because it was there.' Breashears and Salkeld's account (1999) of Mallory's final attempt and ultimate demise on 8 June 1924 near the summit of Earth's highest peak, Last Climb: The Legendary Everest Expeditions of George Mallory, details the physical and mental struggles Mallory endured as he vowed to summit the 'mountain beast' and stand at the top of the world:

As the clouds rolled asunder before the heights, gradually, very gradually, we saw the great mountainsides and glaciers and ridges, now one fragment, now another, through the floating rifts, until, far higher in the sky than imagination dared to suggest, a prodigious white fang an excrescence from the jaw of the world - the summit of Everest, appeared. (p. 81)

Jordan's Mount Everest was the six-month crossing of the Arctic. Not any specific point or experience along the journey - simply the feat of delivering a superior online education program from the Arctic. As the months passed, a feeling of wonder was beating down on Jordan, as it would on even the most hardened of explorers. There were no maps for this feeling and no compasses that pointed home. There was one goal and that was education:

I rarely looked at the website when I came into an Inuit community, I didn't even know how much was going on with the online learning environment. I didn't even know if the photos I was sending were showing up ... I had no idea what was actually going on. It was a feeling of wonder - are all of the files from hours of work showing up on the web for everyone to explore and learn from?

Jordan experienced 'a complete release of power, a release of everything because [he] couldn't check if what [they] were working on was making it to the students or how it looked. At times, I felt lost ... lost in the Arctic.' Nevertheless, there was a single piece of technology that Jordan brought on the expedition, measuring no larger than a deck of cards, which always pointed home.

A capacity of 5000 songs and a battery life of eight playback hours seem like a dream to suffice the daily train or bus commute to the workplace in mainstream suburbia. On the other hand, when 'you have to bargain with yourself to simply take off one glove for 3 or 4 seconds,' eight hours of battery life never seems to do the trick. The unrelenting thought of taking that one glove off again to click the tiny power switch a mere five millimeters toward the off position using your frostbitten fingertip felt 'sometimes too much for a single day.' Apple (2008) humbly reports on their website that the environmental requirements of the iPod portable music player are 32-95 degrees Fahrenheit (0-35 degrees Celsius) for operating temperatures and -4 to 113 degrees Fahrenheit ( -20 to 45 degrees Celsius) for non-operating temperatures. Jordan found these numbers to be slightly padded for the 'public' as he habitually listened to the Counting Crows in his tent, where temperatures at the floor were at times -20 degrees Fahrenheit. The song 'A Long December' (Duritz, 1996) was almost too fitting of Jordan's experience. The song brought Jordan home, stirring up memories of the past and experiences that felt safe and warm ... home-like. Memories of 'individuals that are part of your everyday life and shape your existence.' The familiarity 
that is endlessly crushed by 'the void of existence bearing down on you with every passing mile. What the hell am I doing out here? All I knew was I needed to get the trail report out for the teachers and students.'

\title{
Touching lives through AL
}

At the close of the second interview, Jordan stated 'The reflection of the lives that you are touching, educationally, motivationally, and spiritually, through a presence being served through a cable attached to a computer screen only carries one so far.' For sustainability on the trail, the soul enjoys familiar human contact. On 8 March 2004, as the team approached Baker Lake, Jordan realized what he actually was doing out there - he was touching people's lives:

\begin{abstract}
When I was coming into Baker Lake ... I hadn't seen anyone for 73 days and pretty soon over the horizon came a snow machine. I knew it was a snow machine because the light was jumping up and down. I was very excited about it because I hadn't seen anybody, and number two ... there would be a trail now to get into the next Inuit village. This individual gets off his snow machine and walks over ... I ski to him ... I extend my hand towards him and I say, 'You have no idea how excited I am, my name is [Jordan].'
\end{abstract}

The man said ... 'I know who you are; I recognize your voice from the Internet.'

\section{$\mathrm{AL}$ in the classroom}

Delivering an AL program is a truly rewarding and endearing journey, an endeavor that students and teachers alike can experience firsthand. Through our phenomenological exploration we have discovered that the experience of traversing the Arctic to engage students and teachers from around the world in a truly authentic learning context is saturated with hardships, adversity, privation, and in the end, flourishing collaborative education. From colliding team goals of education, media, and mileage; to generating trail data in a blizzard; to battling satellite technologies in subzero winds; to absolute fatigue from day-to-day responsibilities; to hopeless disorientation with your intended goals, the experience of delivering AL from the Arctic is an intricate, intertwined web of perseverance and education. However, for Jordan, amidst the glacial winds, burnt sleeping bags, technological frustration, frozen hands, team struggles, and sheer exhaustion, 'having the opportunity to reach and collaborate with an amazing audience of learners, educators, and experts through adventure learning was one of the greatest experiences of [his] life.'

\section{Venturing forward: embarking on your own AL experience}

Ultimately, we encourage you, the reader, to embark on your own unique AL experience with your students. This is the future of $\mathrm{AL}$ - where teachers and students are delivering mini-AL projects based on their local region of exploration and sharing their lesson goals and adventures online to collaborate with learners from around the world. To support you in this endeavor, we have applied the principles of AL (Doering, 2006) to a practical sixstep process for designing and implementing these mini-AL environments (see Figure 2):

(1) Define the issue or problem that you and your students wish to investigate.

(2) Identify the geographic location and populations that relate to understanding the issue or problem. 


\section{Adventure Learning Framework}

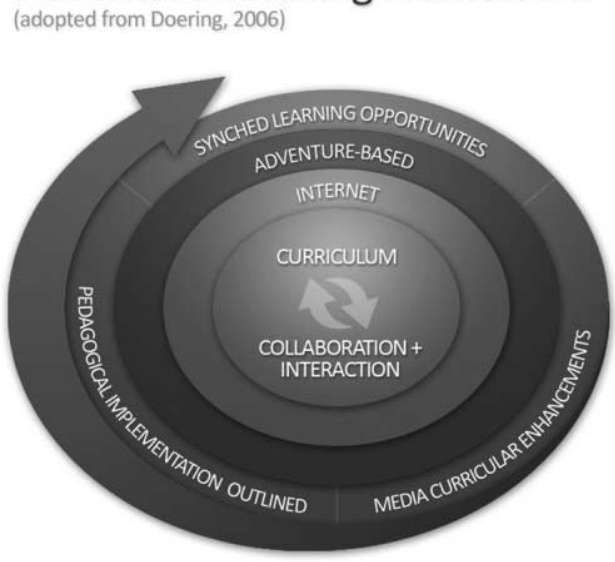

Theory

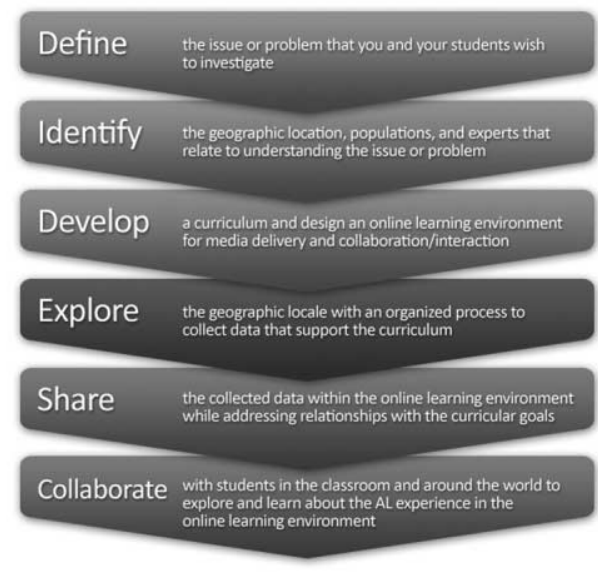

Practice

Figure 2. Adventure learning framework: theory into practice (adopted from Doering, 2006, p. 201).

(3) Develop a curriculum that addresses the issue or problem and create an online adventure space where the collected data can reside and collaboration/interaction can support the investigation.

(4) Explore the geographic locale with an organized process to collect data that support the curriculum.

(5) Share the collected data within the online learning environment while addressing relationships between the data and the curricular goals.

(6) Collaborate with students in the classroom and around the world to explore and learn about the AL experience within the online learning environment.

When learners are collaborating online using authentic media to enhance a curriculum, we will continue to have students motivated to learn at the levels exhibited within the AT2004 program (Doering, 2006). The future of AL begins with giving learners their own AL experience, as they become the designers of the environments - learners as designers - sharing their knowledge throughout the world.

\section{Note}

1. The name has been changed. Unless otherwise cited, all in-text and block quotations are excerpted from interviews with Jordan.

\section{Notes on contributors}

Charles Miller is an assistant professor in the Learning Technologies program at the University of Minnesota. His research focuses on the effects of aesthetics and emotional design on the learner experience, with emphasis on the design and development of technologies that transform the instructional experience.

George Veletsianos, a PhD candidate in Learning Technologies at the University of Minnesota, is interested in the design, development, and evaluation of electronic learning environments. 
Aaron Doering is an assistant professor in the Learning Technologies program at the University of Minnesota. His research focuses on the design, development, and evaluation of hybrid online adventure learning environments, online scaffolding environments, and online community-building environments.

\section{References}

Apple. (2008). iPod classic - Technical specifications. Retrieved May 30, 2008, from http:// www.apple.com/ipodclassic/specs.html

Breashears, D. (1999). High exposure: An enduring passion for Everest and unforgiving places. New York: Simon \& Schuster.

Breashears, D., \& Salkeld, A. (1999). Last climb: The legendary Everest expeditions of George Mallory. Washington, DC: National Geographic.

Doering, A. (2006). Adventure learning: Transformative hybrid online education. Distance Education, $27(2), 197-215$.

Doering, A. (2007). Adventure learning: Situating learning in an authentic context. Innovate, 3(6). Retrieved November 4, 2007, from http://innovateonline.info/index.php?view=article\&id=342\& highlight $=$ doering

Doering, A., \& Veletsianos, G. (2007). An investigation of the use of real-time, authentic geospatial data in the K-12 classroom. Using geospatial data in geographic education [Special issue]. Journal of Geography, 106(6), 217-225.

Doering, A., \& Veletsianos, G. (2008). Hybrid online education in the K-12 classroom: Identifying integration models using adventure learning. Journal of Research of Technology in Education, 41(1), 101-119.

Duritz, A. (1996). A long December [Recorded by Counting Crows]. On Recovering the satellites [Record]. Los Angeles: Geffen Records.

Finch, G. (1922). The second high climb. The Geographical Journal, 60(6), 413-422.

Giorgi, A. (1997). The theory, practice, and evaluation of the phenomenological method as qualitative research procedure. Journal of Phenomenological Psychology, 28(2), 235-260.

Hall, J. (2004). Polarhusky.com. eLearning Advocate. Retrieved January 5, 2005, from http:// homepage.mac.com/elearn

Hassenzahl, M. (2004). Beautiful objects as an extension of the self: A reply. Human-Computer Interaction, 19(4), 377-386.

Husserl, E. (1913). Ideas. London: George Allen and Unwin.

Jonassen, D., Campbell, J., \& Davidson, M. (1994). Learning with media: Restructuring the debate. Educational Technology Research and Development, 42(2), 31-39.

Keys, C., \& Bryan, L. (2001). Co-constructing inquiry-based science with teachers: Essential research for lasting reform. Journal of Research in Science Teaching, 38(6), 631-645.

Kirschner, P., Strijbos, J., Kreijns, K., \& Beers, P.J. (2004). Designing electronic collaborative learning environments. Educational Technology Research and Development, 52(3), 47-66.

Kolb, D. (1984). Experiential learning: Experience as the source of learning and development. Englewood Cliffs, NJ: Prentice Hall.

Norman, D. (1988). The psychology of everyday things. New York: Basic Books.

Patton, M. (2002). Qualitative research and evaluation methods. Thousand Oaks, CA: Sage.

PolarHusky Adventure Learning Expedition. (2004). Arctic Transect 2004. Retrieved April 18, 2005, from http://www.polarhusky.com/2004/public/home.asp?menuID=home

Polkinghorne, D. (1989). Phenomenological research methods. In R.S. Valle \& S. Halling (Eds.), Existential-phenomenological perspectives in psychology: Exploring the breadth of human experience (pp. 41-60). New York: Plenum Press.

Szadkowski, J. (2004, February 8). Canadian Arctic virtual adventure. The Washington Times. Retrieved May 25, 2005, from http://www.washingtontimes.com/functions/print.php?Story $\mathrm{ID}=20040207-101911-9557 \mathrm{r}$

van Manen, M. (1990). Researching lived experience: Human science for an action sensitive pedagogy. New York: State University of New York.

van Manen, M. (2001). Researching lived experience (2nd ed.). London, Ontario, Canada: Althouse Press. 